\title{
ERRATUM
}

\section{Conceptual model of a coastal aquifer system in northern Greece and assessment of saline vulnerability due to seawater intrusion conditions}

\author{
A. Kallioras $\cdot$ F. Pliakas $\cdot$ I. Diamantis
}

Published online: 5 September 2006

(C) Springer-Verlag 2006

\section{Erratum to: Environ Geol DOI 10.1007/s00254-006-0331-0}

Unfortunately, an error occured in the reference:

Kallioras A, Pliakas F, Diamantis I (2004) H

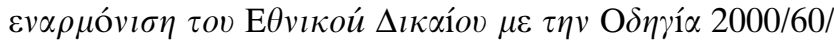
EK $\gamma l \alpha \tau \eta v \pi \rho o \sigma \tau \alpha \sigma i \alpha \kappa \alpha l \delta l \alpha \chi \varepsilon i \rho l \sigma \eta \tau \omega v v \delta \dot{\alpha} \tau \omega v$ (The harmonization of national law with the Directive 2000/ $60 \mathrm{EC}$ for the protection and management of waters), Environment and Law, Nomiki Bibliothiki 4:480-488
The correct reference of this paper is as follows:

Kallioras A, Pliakas F, Petalas C, Diamantis I (2004)

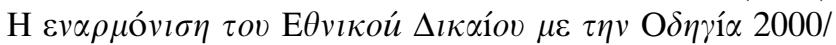
60/EK $\gamma l \alpha \quad \tau \eta v \quad \pi \rho o \sigma \tau \alpha \sigma i ́ \alpha \quad \kappa \alpha l \quad \delta l \alpha \chi \varepsilon i ́ \rho l \sigma \eta \quad \tau \omega v \quad v \delta \alpha \dot{\tau} \tau \omega v$ (The harmonization of national law with the Directive 2000/60 EC for the protection and management of waters), Environment and Law, Nomiki Bibliothiki 4:480-488

The online version of the original article can be found at http://dx.doi.org/10.1007/s00254-006-0331-0.

A. Kallioras $(\varangle) \cdot$ F. Pliakas $\cdot$ I. Diamantis

Department of Civil Engineering,

Democritus University of Thrace,

Xanthi 67100, Greece

e-mail: akall@civil.duth.gr 